\title{
PENINGKATAN KEMANDIRIAN LANSIA MELALUI OKUPASI TERAPI DAN GROUP PSYCHOTHERAPHY DI PSTW SABAI NAN ALUIH SICINCIN PADANG PARIAMAN
}

\author{
H.Sunardi ${ }^{1}$, Renidayati ${ }^{2}$ \\ (Poltekkes Kemenkes Padang) \\ *Correspondence author's email:renidayati72@gmail.com
}

\begin{abstract}
The increasing number of the elderly causes complex problems for the elderly, families and communities. Physiological and psychological changes make the elderly feel useless, experience decreased motivation and independence. One of the efforts to increase the independence of the elderly in order to remain qualified is the application of therapeutic modalities in the form of occupational therapy and group psychotherapy. This study aims to determine the changes in the independence of the elderly before and after Ocupasi therapy and Group Psychotherapy at PSTW Sabai Nan Aluih Sic Cincin, Padang Pariaman Regency. The study used a quantitative approach with "Quasi Experimental pre and post test with control group which was held from March to November 2019. The study sample was 63 elderly people who were taken by purposive sampling." The research instrument used the Katz AD Index. Data analysis used Paired sample $t$-test and Independent $t$ test. The increase in the average independence of the dementia elderly was greater in the elderly who were given Ocupasi therapy and Group Psychotherapy by 18.83 compared to those who received Ocupasi therapy of 7,121 . Conclusion The elderly who received occupational therapy and group psychotherapy experienced an increase in independence compared to the elderly who only received occupational therapy. It is recommended that nursing home nurses receive occupational therapy training modified with group psychotherapy and that the training module needs to be improved.
\end{abstract}

Keywords: occupational therapy; Group Psychotherapy; Independence of parents

\begin{abstract}
Abstrak
Meningkatnya jumlah lansia menyebabkan permasalahan yang kompleks bagi lansia, keluarga dan masyarakat. Perubahan fisiologis dan psikologis membuat lansia merasa tidak berguna, mengalami penurunan motivasi dan kemandirian. Salah satu upaya meningkatkan kemandirian lansia agar tetap berkualitas adalah dengan penerapan terapi modalitas berupa okupasi terapi dan psikoterapi kelompok. Penelitian ini bertujuan mengetahui perubahan kemandirian lansia sebelum dan sesudah terapi Ocupasi dan Psikoterapi Kelompok di PSTW Sabai Nan Aluih Sic Cincin Kabupaten Padang Pariaman. Penelitian menggunakan pendekatan kuantitatif dengan "Quasi Experimental pre and post test with control group yang dilaksanakan pada bulan Maret sampai November 2019. Sampel penelitian 63 lansia yang diambil secara purposive sampling. Instrumen penelitian menggunakan Katz AD Index. Analisis data menggunakan Paired sample t-test dan Independent t test. Peningkatan ratarata kemandirian lansia dimensia lebih besar pada lansia yang diberikan Ocupasi terapi dan Group Psychotheraphy sebesar 18,83 dibanding yang mendapat Ocupasi terapi sebesar 7,121. Kesimpulan Lansia yang mendapatkan ocupasi terapi dan Group Psychotheraphy mengalami peningkatan kemandirian dibandingkan dengan lansia yang hanya mendapat terapi okupasi. Disarankan perawat Panti Jompo mendapat pelatihan terapi okupasi yang dimodifikasi dengan Psikoterapi Kelompok dan perlu perbaikan modul pelatihan tersebut.
\end{abstract}

Kata Kunci : Terapi okupasi; Psikoterapi Kelompok; Kemandirian orang tua 


\section{PENDAHULUAN}

Meningkatnya jumlah lansia akan menimbulkan berbagai permasalahan yang komplek bagi lansia sendiri, keluarga dan masyarakat. Perubahan fisiologis dan psikologis yang terjadi sangat berpengaruh terhadap kemandirian lansia ${ }^{1}$.Kemandirian pada lansia tergantung pada kemampuan status fungsionalnya dalam melakukan aktivitas sehari- hari². Kemandirian lansia dipengaruhi factor umur dan status perkembangan, kesehatan fisiologis, fungsi kognitif, fungsi psikososial, tingkat stres, ritme biologi dan status mental ${ }^{3}$. Perubahan tersebut umumnya mengarah pada kemunduran kesehatan fisik dan psikis sehingga berpengaruh terhadap kemandirian lansia dalam melakukan aktivitas sehari-hari ${ }^{4}$.

Ada beberapa faktor yang berhubungan dengan kemandirian lansia yaitu kondisi kesehatan, kondisi sosial dan ekonominya. Penelitian terhadap 90 orang lansia terdapat hubungan antara usia dengan kemandirian lansia. ${ }^{2}$ Penelitian lain terdapat hubungan kondisi ekonomi dengan kemandirian lansia yakni lansia mandiri memiliki ekonomi mampu lebih banyak $(97,6 \%)$ dibandingkan lansia mandiri yang memiliki ekonomi tidak mampu ${ }^{5}$.Rendahnya tingkat kemandirian lansia berkorelasi positif dengan penurunan kondisi fisik lansia sendiri ${ }^{6}$. Agar dapat hidup secara mandiri lansia harus mampu menyesuaikan diri dengan perubahan ${ }^{7}$. Salah satu upaya yang dapat dilakukan dalam meningkatkan kemandirian lansia agar hidupnya tetap berkualitas dengan melakukan terapi modalitas dalam bentuk terapi okupasi ${ }^{8}$. Terapi Okupasi merupakan suatu bentuk psikoterapi suportif berupa aktivitas-aktivitas yang membangkitkan kemandirian lansia secara manual, kreatif dan edukasional untuk menyesuaikan diri dengan lingkungan dan meningkatkan derajat kesehatan fisik dan mental pasien serta kebermaknaan hidup lansia. ${ }^{9}$.

Terapi okupasi juga berfokus pada kemampuan fungsional lansia dan cara untuk meningkatkan fungsi lansia dengan bekerja dalam bidang seni, kerajinan tangan dan berfokus pada keterampilan psikomotor ${ }^{10}$. Terapi okupasi dapat mengembangkan, memelihara, memulihkan fungsi atau mengupayakan kompensasi/adaptasi untuk aktifitas sehari-hari, produktivitas dan luang waktu melalui pelatihan, remediasi, stimulasi dan fasilitasi dalam meningkatkan kemandirian lansia. ${ }^{2,11}$ Pelaksanaan okupasi terapi dimodfikasi dengan Group Psychotheraphy. Group Psychotheraphy terbukti mampu meningkatkan kemandirian pada lansia ${ }^{12,7}$. Penelitian ini sejalan dengan penelitian yang menunjukkan adanya peningkatan kemandirian pada lansia setelah mengikuti Group Psychotheraphy ${ }^{13,14}$ Group Psychotheraphy dapat menurunkan tingkat depresi pada lansia di Panti Wredha Budhi Dharma Ponggalan Umbulharjo Yogya. Group Psychotheraphy dilakukan pada teman sekelompok yang saling memberikan dukungan atau support (peer support/dukungan kelompok) $)^{15,8}$. 
Berdasarkan data dari Panti Sosial Tresna Werdha Sabai Nan Alui Sicincin tahun 2019, terdapat 110 orang lansia terdiri dari 69 laki-laki dan 41 perempuan yang ditempatkan di 14 wisma. Hasil wawancara dengan tenaga kesehatan mengatakan kemandirian lansia masih rendah.Kegiatan rutin yang dilakukan lansia dalam meningkatkan kemandirian lansia antara lain membuat kerajinan tangan setiap hari senin, wirid dan pengajian setiap hari rabu, senam lansia setiap hari selasa dan kamis, dan gotong royong bersama setiap hari jumat. Namun tidak semua lansia mengikuti kegiatan-kegiatan tersebut secara rutin. Usaha non farmakologis dengan untuk meningkatkan kemandirian lansia masih jarang dilakukan di PSTW Sabai Nan Aluih. Upaya yang dilakukan baru seputar senam bersama, terapi musik dan Terapi aktifitas kelompok yang pelaksanaanya baru dilaksanakan ketika mahasiswa praktek lapangan di PSTW Sabai Nan Aluih Sicincin.

Berdasarkan fenomena di atas telah dilakukan penelitian tentang Peningkatan Kemandirian Lansia melalui Okupasi terapi dan Group Psychotheraphy di PSTW Sabai Nan Aluih Sicincin Padang Pariaman. Dengan tujuan penelitian mengetahui perubahan kemandirian lansia sebelum dan sesudah terapi Ocupasi dan Psikoterapi Kelompok di PSTW Sabai Nan Aluih Sicincin, Kabupaten Padang Pariaman..

\section{METODE PENELITIAN}

Penelitian dilaksanakan di Panti sosial Tresna Werdha Sabai Nan Aluih Sicincin Kab Padang Pariaman bulan Maret sampai Nofember 2019 dengan sampel penelitian 63 orang lansia yang diambil secara purposive sampling. Sampel terdiri dari 30 orang lansia yang diberikan okupasi terapi dan Group Psychotheraphy dan 33 orang untuk lansia yang diberikan okupasi terapi. Instrumen penelitian menggunakan Index Katz AD. Kuesioner Index Katz ADL bertujuan menilai aktivitas kehidupan sehari-hari lansia yang berdasarkan evaluasi fungsi mandiri atau ketergantungannya sehari-hari lansia yang meliputi 17 pertanyaan mengenai mandi, berpakaian, makan, kebersihan diri, mengontrol BAB/BAK, berjalan di lantai datar, ibadah, melakukan pekerjaan rumah, berbelanja, mengelola keuangan, menggunakan sarana transportasi, menyiapkan obat, merencanakan/mengambil keputusan untuk kepentingan keluarga, melakukan aktifitas diwaktu luang. ${ }^{16}$.

Tahap pelaksanaan intervensi kelompok diawali dengan pre test untuk mengukur kemampuan kognitif Lansia pada dua kelompok. Tahapan intervensi pada kelompok pertama diberikan okupasi terapi dan Group Psychotheraphy terdiri dari 4 sesi dimana tiap sesi pelaksanaannya memerlukan waktu 45 - 60 menit, yang dilaksanakan 1-2 kali seminggu. Pada kelompok kedua yang diberikan okupasi terapi sebanyak 1 kali seminggu selama 4 sampai 6 bulan. Tahapan Pos Post test yang diilakukan pada kelompok yang diberikan okupasi terapi dan Group Psychotheraphy dan kelompok yang hanja diberikan okupasi saja. 
setelah semua sesi dalam intervensi selesai. Analisa data dilakukan secara univariat dan bivariate untuk menganalisis perbedaan kemandirian pada lansia dalam 1 kelompok sebelum dan sesudah intervensi menggunakan uji Paired sample $t$ - test, untuk menganalisa perbandingan kemandirian pada kedua kelompok sesudah mendapatkan intervensi menggunakan uji t independent t.test.

\section{HASIL PENELITIAN}

Analisis Univariat

Tabel 1 . Karakteristik Responden Menurut Jenis Kelamin di PSTW Sabai Nan Aluih Sicincin Kab Padang Pariaman Tahun 2019

\begin{tabular}{|c|c|c|c|c|c|}
\hline \multirow[t]{2}{*}{ Karakteristik } & \multicolumn{2}{|c|}{$\begin{array}{c}\text { Kelompok } \\
\text { OPT dan GPT }\end{array}$} & \multicolumn{2}{|c|}{$\begin{array}{l}\text { Kelompok } \\
\text { OPT }\end{array}$} & \multirow[t]{2}{*}{ P Value } \\
\hline & $f$ & $\%$ & $f$ & $\%$ & \\
\hline \multicolumn{6}{|l|}{ Jenis Kelamin } \\
\hline a. Laki- Laki & 17 & 56.7 & 23 & 69.7 & \multirow{2}{*}{0,067} \\
\hline b. Perempuan & 13 & 43.3 & 10 & 30.3 & \\
\hline \multicolumn{6}{|l|}{ Pendidikan } \\
\hline a. Tidak Sekolah & 7 & 23.3 & 15 & 45.5 & \multirow[t]{4}{*}{0,066} \\
\hline b. SD & 20 & 66.7 & 16 & 48.5 & \\
\hline c. SMP & 3 & 10.0 & 2 & 6.1 & \\
\hline d. SMA & 0 & 0 & 0 & 0 & \\
\hline \multicolumn{6}{|l|}{ Aktifitas Sosial } \\
\hline a. Tidak ada & 16 & 53,3 & 26 & 78.8 & \multirow[t]{2}{*}{0,055} \\
\hline b. ada & 14 & 46.7 & 7 & 21.2 & \\
\hline \multicolumn{6}{|l|}{ Lama Tinggal } \\
\hline a. Kurang 5 tahun & 7 & 23.3 & 10 & 30,3 & \multirow[t]{3}{*}{0,054} \\
\hline b. $2-5$ tahun & 14 & 46.7 & 16 & 48.5 & \\
\hline c. Lebih 5 tahun & 9 & 30.0 & 7 & 21,2 & \\
\hline
\end{tabular}

Berdasarkan tabel 1 menunjukkan lebih separoh (56.7\%) responden laki-laki pada kelompok yang mendapat Ocupasi terapi dan Group Psychotheraphy dan lebih separoh $(69,7 \%)$ responden laki-laki Kelompok yang diberikan Ocupasi terapi. Berdasarkan pendidikan sebagian besar (90\%) responden tidak sekolah dan tamat sekolah dasar pada kedua kelompok. Berdasarkan aktifitas sosial lebih separoh $(53,3 \%)$ responden tidak melakukan aktifitas social pada kelompok yang mendapatkan Ocupasi terapi dan Group Psychotheraphy dan sebagaian besar $(78,8 \%)$ responden tidak melakukan aktifitas social pada kelompok yang hanja mendapatkan Ocupasi terapi. Dilihat dari lama tinggal dipanti sebagian besar $(76,7 \%)$ responden telah tinggal di PSTW lebih dari 2 tahun pada kelompok yang mendapat Ocupasi terapi dan Group Psychotheraphy dan lebih separoh (69.7\%) responden telah tinggal di PSTW lebih dari 2 tahun pada kelompok yang diberikan Ocupasi terapi. Hasil Uji kesetaraan karakteristik responden antara kelompok yang mendapatkan 
Ocupasi terapi dan Group Psychotheraphy dan kelompok yang hanja mendapatkan Ocupasi terapi adalah setara ( $p$ value $>0,05)$.

Tabel 2 . Analisis Score kemandirian Responden Sebelum Intervensi di PSTW Sabai Nan Aluih Sicicncin Kab Padang Pariaman Tahun 2019

\begin{tabular}{lllllll}
\hline Kemampuan & Jenis Kelompok & Mean & SD & Min- Maks & $f$ & Pvalue \\
& & & & & & \\
\hline \multirow{2}{*}{ Kemandirian } & OPT dan GPT & 63.67 & 11,88 & $30-65$ & 30 & 0,33 \\
\cline { 2 - 6 } & & & & & & \\
& OPTM & 70.61 & 7.78 & $55-85$ & 33 & \\
\hline
\end{tabular}

Berdasarkan Tabel 2 rata-rata kemandirian responden yang mendapatkan Ocupasi terapi dan Group Psychotheraphy terendah adalah 30 dan tertinggi 65. dengan standar deviasi 11,88. Pada kelompok yang hanja diberikan Ocupasi terapi saja kemandirian terendah 55 dan tertinggi 85. Hasil uji kesetaraan menunjukkan tidak ada perbedaan yang bermakna antara kemandirian kelompok yang mendapat Ocupasi terapi dan Group Psychotheraphy dengan kelompok yang hanja mendapatkan Ocupasi terapi, dengan kata lain kemandirian responden setara pada kedua kelompok ( $P$ value $>0,05$ ).

\section{Analisis Bivariat}

Tabel 3. Kemandirian Responden Sebelum dan sesudah Mendapat Ocupasi terapi dan Group Psychotheraphy di PSTW Sabai Nan Aluih Sicincin 2019

\begin{tabular}{ccccccc}
\hline Variabel & KLP & $f$ & Mean & SD & SE & Pvalue \\
& & & & & & \\
\hline \multirow{2}{*}{ Kemandirian } & Sebelum & 30 & 63,67 & 11,88 & .77311 & 0,005 \\
\cline { 2 - 6 } & Sesudah & 30 & 82.50 & 11,50 & .62372 & \\
\hline & Selisih & \multicolumn{5}{c}{18,83} \\
\hline
\end{tabular}

Berdasarkan tabel 3 rata-rata kemandirian responden sebelum dilakukan intervensi sebesar 63,67 dengan standar deviasi 11,88. Setelah dilakukan Ocupasi terapi dan Group Psychotheraphy didapatkan rata- rata kemandirian responden sebesar 82.50 dengan standar deviasi 11,50. Terdapat peningkatan kemandirian responden sebesar 18.83. Hasil analisis terlihat ada perbedaan kemandirian sebelum dan sesudah intervensi dengan ( $P$ value $<0,05)$.

Tabel 4. Kemandirian Responden Sebelum dan sesudah Ocupasi terapi di PSTW Sabai Nan Aluih Sicincin 2019

\begin{tabular}{|c|c|c|c|c|c|c|}
\hline Variabel & Kelompok & $f$ & Mean & SD & SE & Pvalue \\
\hline \multirow[t]{3}{*}{ Kemandirian } & Sebelum & 33 & 63.48 & 8.969 & 1.561 & \multirow[t]{2}{*}{0,005} \\
\hline & Sesudah & 33 & 70.61 & 7.782 & 1.366 & \\
\hline & Selisih & & .121 & & & \\
\hline
\end{tabular}


Berdasarkan tabel 4 rata-rata kemandirian responden sebelum dilakukan intervensi sebesar 63.48 dengan standar deviasi 8.969. Setelah dilakukan Ocupasi terapi didapatkan rata- rata kemandirian responden sebesar 70.61 dengan standar deviasi 7,782. Terdapat peningkatan kemandirian responden sebesar 7.121. Hasil analisis terlihat ada perbedaan kemandirian sebelum dan sesudah intervensi dengan $(P$ value $<0,05)$.

Tabel 5. Perbedaan kemandirian Responden Sesudah Intervensi Ocupasi terapi dan Group Psychotheraphy dan Kelompok yang hanja diberikan Ocupasi terapi di PSTW Sabai Nan Aluih Sicincin Tahun 2019

\begin{tabular}{ccccccc}
\hline \multirow{2}{*}{$\begin{array}{c}\text { Kemandirian } \\
\begin{array}{c}\text { Setelah } \\
\text { Intervensi }\end{array}\end{array}$} & Kelompok & $\mathrm{N}$ & Mean & SD & SE & P Value \\
\cline { 2 - 5 } & OPT dan GPT & 30 & 82.50 & 11,503 & 2,100 & \\
\cline { 2 - 6 } & OPT & 33 & 70.61 & 7.782 & 1,355 & 0,001
\end{tabular}

Berdasarkan tabel.5 rata- rata kemandirian responden pada kelompok yang diberikan Intervensi Ocupasi terapi dan Group Psychotheraphy setelah intervensi adalah 82.50 dengan standar deviasi 11,503. Rata- rata kemandirian setelah diberikan Ocupasi terapi saja 70,61, dengan standar defiasi 7,782. Hasil uji statistic menunjukkan ada perbedaan kemandirian responden yang diberikan Ocupasi terapi dan Group Psychotheraphy dibandingkan dengan kelompok responden yang diberikan Ocupasi terapi dengan nilai $p$ $=0,001$ ( $\mathrm{P}$ Value $<0,05$ ). Responden yang mendapatkan Ocupasi terapi dan Group Psychotheraphy sesudah intervensi meningkat lebih besar secara bermakna dibanding responden yang hanya mendapat Ocupasi terapi saja.

\section{PEMBAHASAN}

\section{Pengaruh Ocupasi terapi dan Group Psychotheraphy dalam peningkatatan Kemandirian lansia}

Hasil analisis menunjukkan kemandirian lansia yang mengikuti Ocupasi terapi dan Group Psychotheraphy meningkat secara bermakna ( $P$ value $<0,05)$. Kemandirian lansia yang hanja mengikuti Ocupasi terapi juga meningkat secara bermakna ( $P$ value $<0,05$ ). Kemandirian lansia yang mengikuti Ocupasi terapi dan Group Psychotheraphy terlihat lebih tinggi dibandingkan dengan kemandirian lansia yang hanja mendapatkan Ocupasi terapi.Kemandirian adalah kemampuan atau keadaan dimana individu mampu mengurus atau mengatasi kepentingannya sendiri tanpa bergantung dengan orang lain ${ }^{16}$. Kemandirian merupakan sikap individu yang diperoleh secara komulatif dalam perkembangan dimana individu akan terus belajar untuk bersikap mandiri dalam 
menghadapi berbagai situasi di lingkungan, sehingga individu mampu berfikir dan bertindak sendiri ${ }^{17}$.

Kemandirian pada lansia meliputi kemampuan lansia dalam melakukan aktivitas sehari-hari, seperti: mandi, berpakaian rapi, pergi ke toilet, berpindah tempat, dapat mengontrol Buang Air Kecil (BAK), atau Buang Air Besar (BAB), serta dapat makan sendiri. Kemandirian juga dipengaruhi oleh perubahan situasi kehidupan, aturan sosial, usia dan penyakit ${ }^{18}$. Hasil penelitian yang dilakukan menunjukan ada hubungan tingkat kemandirian lansia dengan umur. Semakin bertambah usia lansia maka tingkat kemandiriannnya semakin berkurang. Hasil penelitian ${ }^{19}$ tentang tingkat kemandirian pasien lansia di Panti werdha Sabai Nan Aluih menyatakan bahwa gambaran tingkat kemandirian dalam melakukan Aktivitas Kehidupan Sehari-hari (AKS) usia lanjut $(45,5 \%)$ berada pada tingkat mandiri dan $(54,5 \%)$ berada pada tingkat tidak mandiri. Jumlah usia lanjut yang tidak mandiri memiliki jumlah yang lebih besar dibandingkan dengan yang mandiri. Rendahnya tingkat kemandirian lansia berkorelasi positif dengan penurunan kondisi fisik lansia sendiri.

Hasil penelitian yang dilakukan menyatakan bahwa lansia yang tinggal di panti werdha lebih banyak laki- laki. Hal ini senada penelitian yang dilakukan Suhartini pada tahun 2004 di Kelurahan Jambangan Surabaya yang menyatakan bahwa sebagian besar usia lanjut di wilayah tersebut berjenis kelamin laki-laki. Faktor jenis kelamin mempunyai dampak sangat besar terhadap tingkat kemandirian. Walaupun wanita hidup lebih lama dari pria, akan tetapi mereka cenderung mengalami disabilitas, mereka tampak lebih tua dibandingkan pria pada usia yang sama ${ }^{20}$. Wanita usia lebih dari atau sama dengan 70 tahun cenderung mempunyai problem kesehatan yang lebih tinggi dibanding laki-laki pada usia yang sama. Meskipun lansia secara alamiah mengalami penurunan dan kemunduran fisik, tetapi tidak menutup kemungkinan lansia dapat melakukan aktivitas dan pemenuhan kebutuhan sehari-hari secara mandiri ${ }^{16}$. Agar dapat hidup secara mandiri lansia harus mampu menyesuaikan diri dengan perubahan-perubahan yang terjadi. Lansia dapat mengisi waktu luang dengan berbagai aktifitas ${ }^{12}$.

Dalam meningkatkan kemandirian lansia agar hidupnya tetap berkualitas adalah dengan melakukan terapi modalitas dalam bentuk terapi okupasi ${ }^{21}$. Terapi okupasi atau terapi kerja merupakan suatu ilmu dan seni pengarahan partisipasi lansia untuk melaksanakan tugas tertentu yang telah ditetapkan ${ }^{21},{ }^{11}$. Penelitian ini juga didukung penelitian $^{20}$ menyatakan terapi okupasi dapat mengembangkan, memelihara, memulihkan fungsi atau mengupayakan kompensasi/adaptasi untuk aktifitas sehari-hari, produktivitas dan luang waktu melalui pelatihan, remediasi, stimulasi dan fasilitasi dalam meningkatkan kemandirian lansia dalam berbagai aspek . 
Hasil penelitian yang telah dilakukan didapatkan bahwa tingkat kemandirian lansia meningkat di PSTW Sabai Nan aluih Sicincin setelah dilakukan Ocupasi terapi dan Group Psychotheraphy. Dengan dilakukan ocupasi terapi dan dikombinasikan dengan Group Psychotheraphy, lansia saling memberikan dukungan atau support (peer support/dukungan kelompok), yang bermanfaat dan berfokuskan pada prinsip memberi dan menerima, mengaplikasi keterampilan swabantu (self help) serta pengembangan pengetahuan, berhubungan dengan fungsi secara psikologis dan peningkatan kemandiriannya.

Penelitian $^{20}$ menyatakan terapi okupasi dapat mengembangkan, memelihara, memulihkan fungsi atau mengupayakan kompensasi/adaptasi untuk aktifitas sehari-hari, produktivitas dan luang waktu melalui pelatihan, remediasi, stimulasi dan fasilitasi dalam meningkatkan kemandirian lansia dalam berbagai aspek. Terapi ini dapat diberlakukan dan dilakukan di mana saja dan oleh siapa saja. Hasil penelitian yang dilakukan didapatkan hasil bahwa Ocupasi terapi dan Group Psychotheraphy yang dilakukan tiga kali pertemuan selama 60 menit membantu lansia di Panti Werdha fokus pada kenangan masa lalu yang positif daripada memikirkan pengalaman hidup negatif, dapat membantu meningkatkan emosional keseluruhan kesejahteraan orang tua berjuang pada masa transisi. ${ }^{11}$.Hasil penelitian terlihat ada peningkatan yang bermakma kemandirian lansia dalam hal kegiatan untuk makan (feeding) sebesar 2,5 point, peningkatan dalam mandi (bathing) sebesar 6,67 point, perawatan diri (grooowing) 6,67, berpakaian (dressing) 2,1 point ,bowel sebesar 2,27, pengguanan toilet sebesar 1,5 point, transfer 1,33 point , mobilitas 3,5 point dan kemampuan naik turun tangga 2,67. Secara keseluruhan peningkatan kemandirian ansia sebelum dan sesudah intervensi adalah sebesar 29,21.

Berdasarkan hasil penelitian yang dilakukan Ocupasi terapi dan Group Psychotheraphy yang sudah dimodifikasi membantu lansia meningkatkan kemandiriannya sehingga menjadi lebih baik dari keadaan sebelumnya. Selain itu Ocupasi terapi dan Group Psychotheraphy mampu membuat lansia bersosialisasi dengan lingkungan karena terapi modifikasi ini sengaja di setting agar lansia tidak hanya dapat mengingat kembali masa lalunya, namun diharapkan lansia juga mampu kembali berinteraksi dan bersosialisasi dengan lingkungan sekitarnya. Terapi modifikasi ini juga membuat lansia bisa bergerak aktif karena terapi ini menjadikan lansia sebagai subyek utama dalam pelaksanaan terapi okupasi. Modifikasi program yang diberikan kepada lansia juga mampu meningkatkan persepsi kebermaknaan hidup lansia, mengurangi stress, meningkatkan produktifitas dan keterampilan lansia.

Walaupun Ocupasi terapi dan Group Psychotheraphy terlihat tidak berisiko atau tidak berbahaya, terapi ini ternyata juga memiliki risiko komplikasi dan hasil yang tidak diinginkan. Beberapa kerugian yang harus dipertimbangkan sebelum memulai program 
terapi kelompok ini antara lain, kelompok mengharuskan seseorang untuk berbicara atau menjalin hubungan dekat dengan orang lain. Beberapa lansia dapat membutuhkan waktu yang lama sebelum mereka dapat merasa nyaman dan mempercayai anggota kelompok lain. Dampak yang dimunculkan dapat diminimalkan dengan pemberian reinforcement dan reward yang teapt dan sesuai pada lansia.

Hasil penelitian yang telah dilakukan dan didukung hasil penelitian terdahulu membuktikan Ocupasi terapi dan Group Psychotheraphy berpengaruh dalam meningkatkan kemandirian lansia. Baik dalam hal feeding, bathing, grooming, dressing, bowel, pengunaaan toilet, tranfer dan mobitas. Hal ini didukung pelaksanaan latihan dikomunikasikan secara terbuka dengan lansia, kontrak yang jelas dan pemberian reinforment positif senantiasa diberikan kepada lansia dan dilaksanakan dengan suasana yang menyenangkan bagi lansia.

\section{KETERBATASAN PENELITIAN.}

Peneliti menyadari keterbatasan penelitian ini disebabkan beberapa faktor, meliputi; kuesioner yang digunakan dalam penelitian ini belum mempunyai nilai baku. Instrumen disusun berdasarkan teori-teori yang peneliti kembangkan pada tinjauan pustaka. Modul yang digunakan untuk membantu pelaksanaan terapi Ocupasi terapi dan Group Psychotheraphy disusun peneliti sendiri dengan mengacu pada berbagai literatur. Variabel yang diteliti terbatas kepada kemandirian lansia lansia sebagai variabel dependen dan Ocupasi terapi dan Group Psychotheraphy sebagai variabel independen. Ada variabel lain yang perlu diteliti, yakni dukungan keluarga, kondisi fisik, aktivitas lansia atau penyakit penyerta yang dialami lansia di panti werhda.

\section{SIMPULAN DAN SARAN}

Simpulan hasil penelitian didapatkan ada perbedaan bermakna rata-rata kemandirian lansia sebelum dan sesudah diberi Ocupasi terapi dan Group Psychotheraphy dengan kelompok yang diberikan Ocupasi terapi. Peningkatan rata-rata kemandirian lansia dimensia lebih besar pada lansia yang diberikan Ocupasi terapi dan Group Psychotheraphy sebesar 18,83 dari Pada kelompok yang hanya mendapat Ocupasi terapi terdapat peningkatan kemandirian sebesar 7,121. Lansia yang mendapatkan ocupasi terapi dan Group Psychotheraphy sesudah intervensi meningkat kemandiriannya secara bermakna dibanding lansia yang hanya mendapat Ocupasi terapi saja.Disarankan melalui Pimpinan PSTW Sabai Nan Aluih Sicincin agar perawat atau pertugas kesehatan yang bekerja di Panti Werdha perlu mendapatkan pelatihan tentang ocupasi terapi dan Group Psychotheraphy, dan menerapkannya pada kelompok lansia dengan berpedoman kepada modul ocupasi terapi dan Group Psychotheraphy 
yang telah ada.Penyempurnaan modul ocupasi terapi dan Group Psychotheraphy perlu dilakukan sebagai salah satu intervensi pada dalam upaya peningkatan kemandirian lansia.

\section{DAFTAR PUSTAKA}

1. Jumita R, Azrimaidaliza, Machmud R. Kemandirian Lansia Wilayah Kerja Puskesmas Lampasi Kota Payakumbuh. J Kesehat Masy. 2012;6(2):86-94.

2. Hamzah H. Pengaruh Terapi Modalitas Okupasi terhadap Tingkat Kemandirian Lansia di Panti Sosial Tresna Wedha Gau Mabaji Kab. Gowa. 2014.

3. Rohaedi S, Putri ST, Karimah AD. Tingkat Kemandirian Lansia Dalam Activities Daily. Tingkat Kemandirian Lansia Dalam Act Dly. 2016.

4. Silvana H, Djafri D, Dayati R. Factor Related to The Anxiety Level of Elderly With Chronic Disease in Kabupaten Sijunjung 2019. NERS $J$ Keperawatan. 2019;15(2):110. doi:10.25077/njk.15.2.110-118.2019

5. Cahyono AD. HUBUNGAN TINGKAT KEMANDIRIAN LANSIA DALAM MELAKUKAN AKTIVITAS SEHARI-HARI DENGAN TINGKAT KECEMASAN. J AKP. 2013.

6. Dede N. Buku Ajar Keperawatan Gerontik. Jilid 1. Jakarta timur: Trans Infor Medika; 2016.

7. Rohaedi S, Putri ST, Karimah AD. Tingkat Kemandirian Lansia Dalam Activities Daily. Tingkat Kemandirian Lansia Dalam Act Dly. 2016;2(1):17.

8. Slamet Rohaedi, Suci Tuty Putri ADK. Tingkat Kemandirian Lansia Dalam Activities Daily Living Di Panti Sosial Tresna Werdha Senja Rawi. J Pendidik Keperawatan Indones. 2016. doi:10.17509/JPKI.V2I1.2848.G1883

9. Terms KS, On S. Supplemental Table 1. Key Search Terms for the Systematic Review of Fall Prevention Interventions for Community-Dwelling Older Adults The American Journal of Occupational Therapy, July / August 2018 , Volume 72 , Number 4 Supplemental Table 2 . Evidence. 2018;72(4):1-22.

10. Fisher AG, Atler K, Potts A. Effectiveness of occupational therapy with frail community living older adults. Scand J Occup Ther. 2017;14(4):240-249. doi:10.1080/11038120601182958

11. Videbeck SL. Psychiatric Mental Health Nursing. 3rd ed. Philadhelpia: Lippincott. Williams \& Wilkins; 2018.

12. Stuart GW. Principles and Practice of Psychiatric Nursing. 10th ed. Philadelphia: Elsevier Mosby; 2013.

13. Molinari V. Life Review Reminiscence in the Elderly: A Review of the Literature. 2016;(January 1984). doi:10.2190/K4MG-9VYG-WQL3-CBRH

15. Sincihu $\mathrm{Y}$, Dewi BDN. Peningkatan kemandirian lansia berdasarkan perbedaan 
activities daily living: Perawatan lansia di rumah dan di panti werda. Temu IIm Konsep Mutakhir Tatalaksana Berbagai Persoalan Medis. 2015:190-211.

16. Maryam S. Mengenal Usia Lanjut. Jakarta Selatan: Salemba Medika; 2011.

17. National Institute for Health and Care Excellence. NICE guideline [NG32]. Older people: Independence and mental wellbeing. 2015;(December 2015).

18. Jessie Windya. Hubungan Tingkat Kemandirian Dalam Activity Daily Living ( Adl ) Dengan Tingkat Depresi Pada Lansia Di Graha Werdha Marie Joseph Pontianak Dan Graha Jessie Windya Niko Nim I32112012 Program Studi IImu Keprawatan. 2016.

19. Alfyanita A, Matini R D KH. Hubungan Tingkat Kemandirian dalam Melakukan Aktivitas Sehari-hari dan Status Gizi pada Usia Lanjut di Panti Sosial Tresna Werdha Sabai Nan Aluih Sicincin (skripsi). J Kesehat Andalas. 2016;5(1):201-208.

20. Kumar SS, Batra V. Occupational therapy perspective for enhancing functional independence in geriatric population. 2017;3(4):134-136.

21. Sivertsen H, Bjørkløf GH, Engedal K, Selbæk G, Helvik AS. Depression and quality of life in older persons: A review. Dement Geriatr Cogn Disord. 2015;40(5-6):311-339. doi:10.1159/000437299 